\title{
Social functioning and emotion recognition in adults with triple $X$ syndrome
}

Maarten Otter, Peter M. L. Crins, Bea C. M. Campforts, Constance T. R. M. Stumpel, Thérèse A. M. J. van Amelsvoort and Claudia Vingerhoets

\section{Background}

Triple $X$ syndrome (TXS) is caused by aneuploidy of the $X$ chromosome and is associated with impaired social functioning in children; however, its effect on social functioning and emotion recognition in adults is poorly understood.

\section{Aims}

The aim of this study was to investigate social functioning and emotion recognition in adults with TXS.

\section{Method}

This cross-sectional cohort study was designed to compare social functioning and emotion recognition between adults with TXS $(n=34)$ and an age-matched control group $(n=31)$. Social functioning was assessed with the Adult Behavior Checklist and Social Responsiveness Scale for Adults. Emotion recognition was assessed with the Emotion Recognition Task in the Cambridge Neuropsychological Test Automated Battery. Differences were analysed by Mann-Whitney U-test.

\section{Results}

Compared with controls, women with TXS scored higher on the Adult Behavior Checklist, including the Withdrawn scale $(P<0.001$, effect size 0.4) and Thought Problems scale $(P<0.001$, effect size 0.4); and higher on the Social Responsiveness Scale for Adults, indicating impaired social functioning $(P<0.001$, effect size 0.5$)$ In addition, women with TXS performed worse on the Emotion
Recognition Task, particularly with respect to recognising sadness $(P<0.005$, effect size 0.4$)$, fear $(P<0.01$, effect size 0.4$)$ and disgust $(P<0.02$, effect size 0.3$)$.

\section{Conclusions}

Our findings indicate that adults with TXS have a higher prevalence of impaired social functioning and emotion recognition. These results highlight the relevance of sex chromosome aneuploidy as a potential model for studying disorders characterised by social impairments such as autism spectrum disorder, particularly among women.

\section{Keywords}

Triple X syndrome; autistic spectrum disorders; genetics; sex chromosomal disorder; emotion recognition.

\section{Copyright and usage}

(c) The Author(s), 2021. Published by Cambridge University Press on behalf of the Royal College of Psychiatrists. This is an Open Access article, distributed under the terms of the Creative Commons Attribution-NonCommercial-NoDerivatives licence (http://creativecommons.org/licenses/by-nc-nd/4.0/), which permits non-commercial re-use, distribution, and reproduction in any medium, provided the original work is unaltered and is properly cited. The written permission of Cambridge University Press must be obtained for commercial re-use or in order to create a derivative work
Triple X syndrome (TXS) is a genetic syndrome first described back in 1959 in an infertile woman. ${ }^{1}$ TXS is characterised by a 47, XXX karyotype and has an estimated incidence of 1 in 1000 newborn girls. ${ }^{2}$ The phenotype associated with TXS is variable, but is generally mild; therefore, estimates suggest that only $16 \%$ of cases are clinically diagnosed. ${ }^{3}$ Individuals with TXS typically present with tall stature, seizure susceptibility, urogenital abnormalities, reduced fertility ${ }^{2,4}$ and an increased prevalence of several psychiatric conditions, including anxiety, depression and psychotic disorders. ${ }^{2}$

The majority of women with TXS have a full-scale IQ in the low end of the average range, as well as a verbal IQ that is generally lower than their performance IQ. ${ }^{2}$ The behavioural phenotype (increased anxiety, depressive disorder, attention deficits, and delayed speech and language development) and cognitive phenotype (poorer performance on verbal tasks and executive function deficits) are described primarily in children, adolescents and young adults, and the samples were often biased. ${ }^{2,5}$ Therefore, how the phenotype develops when these women reach adulthood is largely unknown, although in a small biased sample, emotional problems, increased levels of anxiety, low self-esteem and social problems were reported. ${ }^{6}$ The phenotype of adults with TXS appears to not be very distinct, illustrated by the fact that they are typically diagnosed after, for example, recurrent abortions or diagnosis of a family member. As a result, cases can go undiagnosed, even in our clinical practice. $^{7}$ However, case reports of adult women with TXS suggest a higher prevalence of traumatic experience, suicidal tendencies, psychosis and/or autism spectrum disorder (ASD), ${ }^{8}$ and adults with TXS can have a relatively poor socioeconomic position. For example, a Danish study found that women with TXS were significantly less likely to have a partner, become a mother or achieve a higher education compared with a control group; moreover, the authors found that women with TXS were more likely to retire at a younger age compared with the control group. ${ }^{9}$ Nevertheless, more research into the adult TXS phenotype is clearly warranted.

TXS has also been associated with impaired social functioning, a key characteristic in several neurodevelopmental, psychiatric and neurological disorders. ${ }^{10,11}$ The biological mechanisms underlying impaired social functioning are currently unknown; however, a growing body of evidence suggests that the sex chromosomes may play a role via haploinsufficiency, ${ }^{12}$ differences in the spatial organisation of chromosomes in the nucleus, ${ }^{13}$ or an increased dosage of $\mathrm{X}$-linked and/or autosomal genes. ${ }^{14-18}$ Indeed, an increased prevalence of ASD has been reported in disorders resulting from either an increase or decrease in the number of sex chromosomes, including TXS, Klinefelter syndrome (47,XXY), Jacobs syndrome (47,XYY) and Turner $(45, \mathrm{X} 0)$ syndrome. ${ }^{5,14}$ Therefore, sex chromosome disorders, such as TXS, may serve as valuable genetic models for studying impaired social functioning in ASD. For example, in a multicentre longitudinal study, a total of 200000 newborn children were screened for a sex chromosome disorder, ${ }^{19-22}$ and unbiased cases of a sex chromosome disorder were followed through young adulthood (for review, see Otter et $\mathrm{al}^{2}$ ), revealing that girls and young women with TXS often have difficulties forming meaningful interpersonal relationships. ${ }^{22}$ Researchers at one of the 
participating centres (the University of Edinburgh) studied the psychiatric symptoms and behavioural characteristics in adolescent and young women ( $\geq 16$ years of age) with TXS and found that four of the 14 young women with TXS had fair, poor or grossly inadequate friendships compared with none of the young women in the control group; in addition, five of the 14 young women with TXS (35.7\%) were found to lead an isolated life compared with only $4 \%$ of the control group. ${ }^{23}$ Another participating centre (Denver, Colorado) followed 11 individuals with TXS from birth to adolescence/early adulthood, and reported social reticence in two of these 11 individuals $(18.2 \%)$ compared with $0 \%$ in the control group. ${ }^{24}$

Furthermore, recent studies found that girls with TXS have higher levels of shyness, social dysfunction and social anxiety, and a high prevalence of autism-like features. ${ }^{25,26}$ Moreover, a recent self-report study, in which adults with TXS used the Symptom Checklist-90 Revised, found that women with TXS have an increased risk of social deficits, although approximately half of the participants did not report any behavioural or social deficits ${ }^{6}$; in contrast, approximately one in 200 women in the general population have ASD. ${ }^{14}$ Moreover, the Symptom Checklist-90-Revised is not considered a suitable tool for diagnosing or ruling out $\mathrm{ASD}^{27}$ In addition, women with social communication difficulties often find it hard to self-identify these difficulties. Taken together, these studies suggest that the prevalence of social impairments is higher among adults with TXS compared with controls; however, studies performed to date regarding impaired social functioning were not designed specifically to assess ASD and/or limited their reporting to relatively young adults.

The social impairments associated with TXS may be, in part, attributable to a delay in the development of speech and/or language, ${ }^{2,5,28}$ as well as impaired cognitive processes such as attention and executive functioning, ${ }^{29}$ two cognitive domains that have been associated with ASD. However, little is currently known regarding social cognition in adults with TXS. Social cognition encompasses all of the cognitive processes that are required for social functioning. Moreover, the ability to recognise emotions is an important part of social cognition and is required for adequate social functioning, including the ability to form and maintain personal relationships. Although impaired emotion recognition has been reported in other sex chromosome disorders, including Klinefelter and Turner syndrome, ${ }^{30-32}$ to date no studies have examined emotion recognition in adults with TXS.

\section{Aim}

Given that social impairments and a high prevalence of autism-like traits have been observed in girls and young women with TXS, TXS may serve as a valuable model for studying neurodevelopmental disorders such as ASD. Therefore, the aim of this study was to examine social functioning in adults with TXS by assessing a broad range of social behaviours generally associated with ASD, including social motivation, social communication, social awareness and rigidity, and repetitive behaviours; in addition, we examined whether women with TXS have impaired social cognition. We therefore tested the hypothesis that women with TXS have a lower level of social functioning and reduced emotion recognition compared with age-matched controls.

\section{Method}

\section{Ethical statement}

All procedures in this study were performed in accordance with the ethical standards established by the respective national and institutional committees regarding human experimentation and in accordance with the Declaration of Helsinki. In addition, all procedures involving human subjects were approved by the medical ethics committee at Maastricht University Medical Centre and Maastricht University (approval number: NL46871.068.14/ METC143051). Written informed consent was obtained from all participants.

\section{Participants}

A total of 65 adult women aged 18-63 years participated in the study; 34 women had TXS (defined as a 47,XXX chromosomal composition determined by conventional karyotyping), and 31 were age-matched controls. To be eligible to participate in this study, participants had to be capable and competent to give informed consent, and had to be sufficiently proficient in the Dutch language.

All 65 participants were White. In the TXS group, ten of the women were diagnosed prenatally, whereas the remaining 24 women were diagnosed postnatally because of the following indications: infertility/recurrent abortions $(n=9)$, atypical development $(n=6)$, a family member with a genetic condition $(n=4)$, small head $(n=2)$, intestinal malformation $(n=1)$, nuchal oedema $(n=1)$ and epicanthal folds $(n=1)$.

\section{Recruitment and assessment}

Participants with TXS were recruited through flyers, digital newsletters, social media, a TXS support group in The Netherlands, advertising and via the Department of Clinical Genetics at Maastricht University Medical Centre. Healthy age-matched controls were recruited through the families and friends of women with TXS and through advertising. Where possible, all assessments were performed within 1 day.

\section{Study design and setting}

This cross-sectional cohort study including an age-matched control group was conducted at the University of Maastricht in Maastricht, The Netherlands.

\section{Instruments}

Full-scale intelligence quotient

Full-scale IQ was estimated with a shortened version of the Dutch Wechsler Adult Intelligence Scale, Third Edition. ${ }^{33}$

\section{Social functioning}

The Adult Behavior Checklist (ABCL) evaluates 134 behaviour problem items in the preceding 6 months. Behaviour problem statements were scored on a three-level rating scale ('absolutely not true', 'somewhat or sometimes true' or 'very true or often true') by someone who knows the participant well. ${ }^{34,35}$ The Withdrawn and Thought Problems scales were shown in a Dutch study to provide a reliable measure of ASD. ${ }^{35}$ Because norms differ between participants aged 18-35 years and participants aged 35-59 years, we present T-scores and three ranges (normal, borderline and clinical), with higher scores representing increased levels of behavioural problems.

A Dutch translation of the informant/observer version of the Social Responsiveness Scale for Adults (SRS-A) was used to screen for ASD-related social problems; this translated version has been shown to have psychometric properties comparable to the original version. ${ }^{36,37}$ For our study, we chose the informant version of the SRS-A, as women with social communication difficulties often find it hard to self-identify these difficulties, and therefore often underestimate their own level of social difficulties. The SRS-A has 

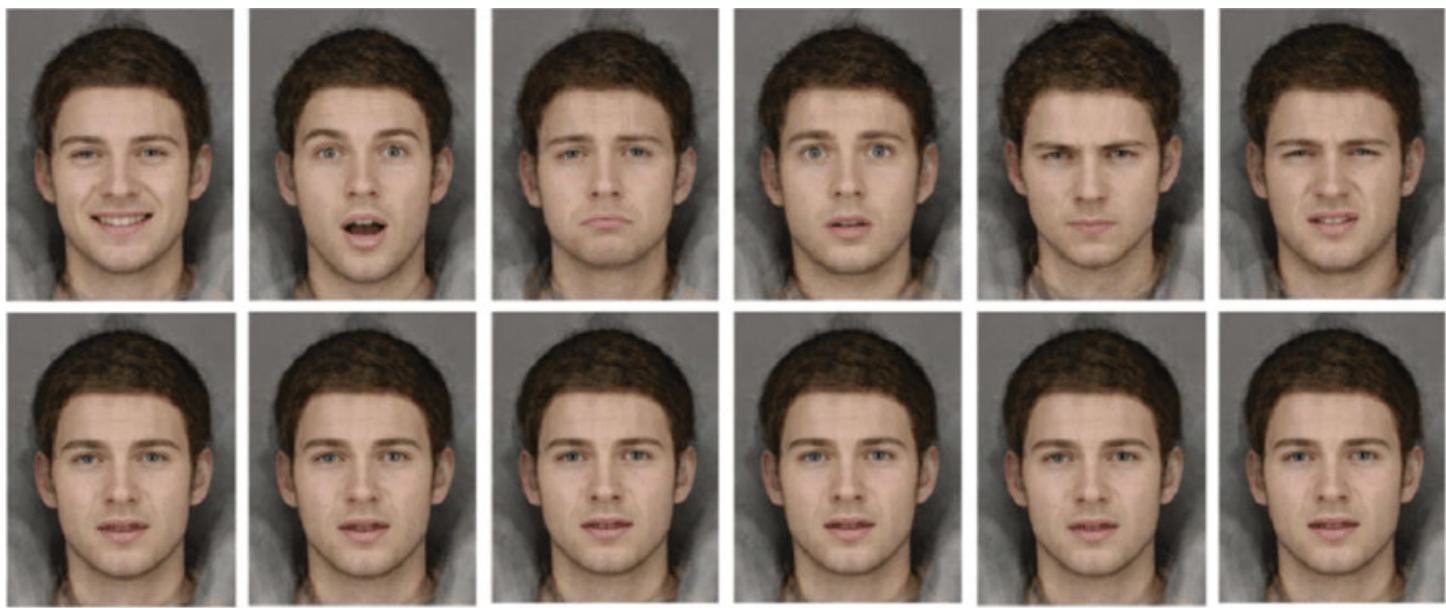

Happiness

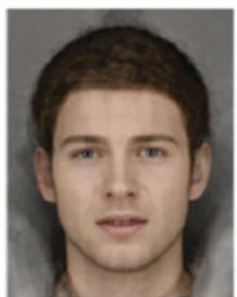

Sadness

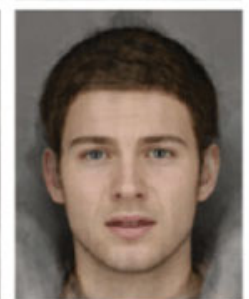

Fear

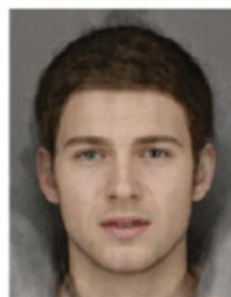

Anger

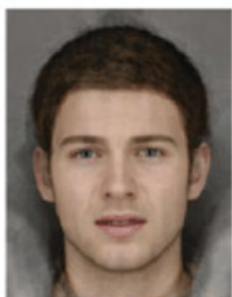

Disgust

Fig. 1 The Emotion Recognition Task (ERT) from CANTAB. Permission to replicate this figure has been given to the authors by Cambridge Cognition Ltd.

64 questions divided among the following four subscales: social motivation, social communication, social awareness and rigidity, and repetitive behaviour. ${ }^{37,38}$ The SRS-A was completed by a family member, partner or significant other. Symptoms were rated on a four-point Likert scale, with scores ranging from 0 (not true) to 3 (almost always true), and T-scores are presented. A higher score represents more difficulties in social responsiveness. Seventeen of the 64 items required reverse coding. ${ }^{37,38}$ The Tscores reflect the following levels of clinical severity: high functioning (T-score 0-39), normal functioning (T-scores 40-59), mild-tomoderate deficits (T-scores 60-74) and severe deficits (T-scores $\geq 75){ }^{37,38}$ Although the SRS-A is not considered a diagnostic instrument, severe deficits on this scale are often associated with a diagnosis of autism in clinical practice. ${ }^{39}$

\section{Emotion recognition}

The Emotion Recognition Task (ERT) in the Cambridge Neuropsychological Test Automated Battery for Windows (Cambridge Cognition, Cambridge, UK; see www. cantab.com) was used to assess the participants' ability to identify the following six emotions: happiness, sadness, anger, disgust, fear and surprise. During the ERT, the participants were shown two series of 90 facial expressions depicting various intensities of these six emotions (Figs 1 and 2), with 15 levels of intensity per emotion. The task procedure was as follows: a fixation cross was displayed in the centre of an otherwise black screen for 1.5 to $2.5 \mathrm{~s}$, then a stimulus showing a face depicting one of six possible emotions was shown briefly $(200 \mathrm{~ms})$. The stimulus was then masked with a speckled grey rectangle for $250 \mathrm{~ms}$. After masking, six buttons were displayed and the participant had to choose the button which they thought most closely corresponded to the shown emotion. Participants were instructed not to overthink and to respond as quickly as possible. Correct identifications of the separate emotions and total correct identifications were recorded. The ERT was performed as described previously. ${ }^{40}$

\section{Statistical analyses}

Normally distributed data (age, full-scale IQ score and ERT total score) were compared with the Student's $t$-test. Non-normally distributed data (ABCL T-score, SRS-A T-score and ERT data) were compared with the Mann-Whitney $U$-test. Categorical data were analysed by Fisher's exact test. Spearman's rank correlation coefficients were calculated between the total SRS-A scores and full-scale IQ scores.

ERT scores were transformed into standardised Z-scores to identify potential outliers defined as a Z-score smaller than -3 or larger than 3; no outliers were identified. Spearman's rank correlation coefficients were also calculated between the total ERT score and age, and between the total ERT score and full-scale IQ. In addition, an analysis of covariance (ANCOVA) was performed to examine the effect of full-scale IQ on ERT performance. Spearman's rank correlation coefficients were also calculated between the social motivation subscale of the SRS-A and total ERT score.

Differences between the women who were diagnosed with TXS prenatally and the women who were diagnosed with TXS postnatally were also analysed, to determinate the level of ascertainment bias between these two groups. These differences were analysed with the Student's $t$-test (full-scale IQ), the Mann-Whitney $U$-test (SRSA total score) and an ANCOVA (ERT total score, controlling for full-scale IQ as a potential confounder).

All statistical analyses were two-tailed and were performed with Stata for Mac version 13.1 (StataCorp, College Station, Texas). Variables that were normally distributed are reported as the mean, s.d. and 95\% confidence interval; variables that were nonnormally distributed are reported as the median and interquartile range (IQR). Differences with a $P$-value $<0.05$ were considered significant.

\section{Results}

We found no significant difference in age between the TXS group and the control group (Table 1). In contrast, we found that fullscale IQ was significantly lower in the TXS group compared with the control group (Table 1).

\section{Social functioning}

The ABCL T-scores were significantly higher in the TXS group ( $n=$ 33) compared with the control group $(n=31)$ on the Withdrawn syndrome scale (median 64, IQR 55-69 v. median 55, IQR 50-61, respectively; $P<0.001$, effect size 0.4 ) and the Thought Problems syndrome scale (median 59, IQR 54-66 v. median 50, IQR 50-56, 


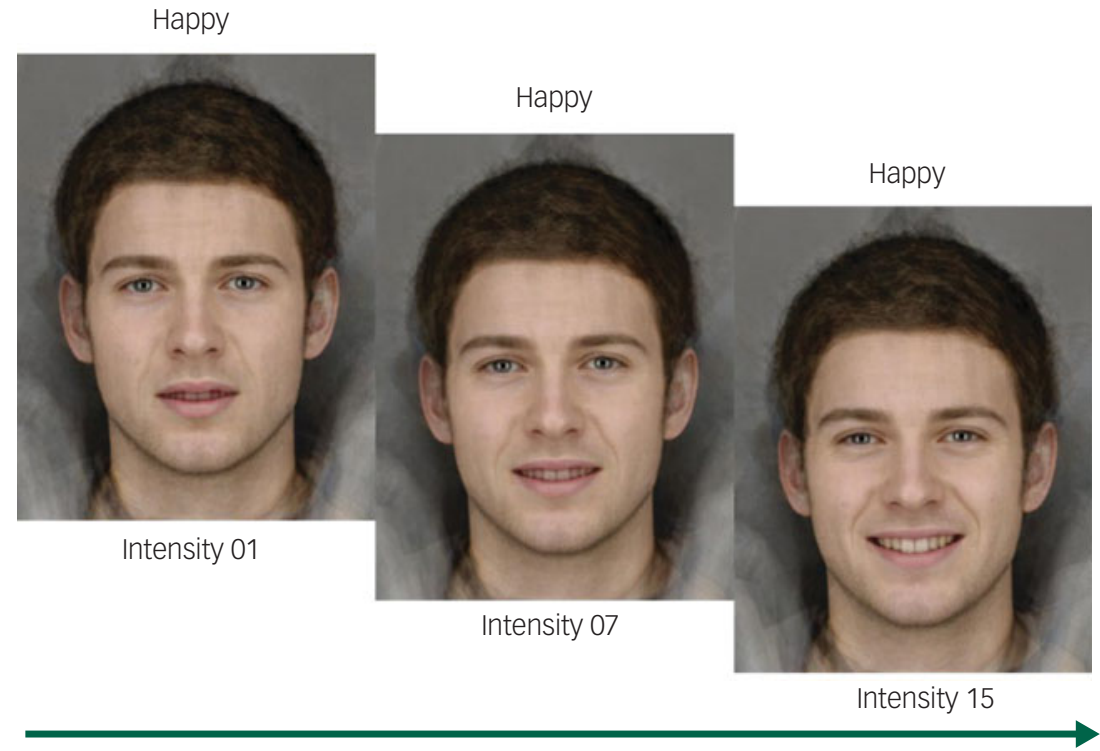

Fig. 2 Three out of 15 intensity levels from the Emotion Recognition Task (ERT). Permission to replicate this figure has been given to the authors by Cambridge Cognition Ltd.

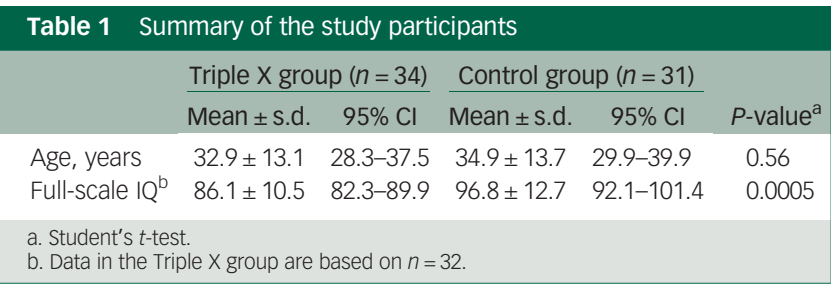

respectively; $P<0.001$, effect size 0.4 ). Similar results were obtained when we excluded the two participants who were $>59$ years of age (data not shown). With respect to the results of the Withdrawn syndrome scale, $60.6 \%, 15.2 \%$ and $24.2 \%$ of the women in the TXS group scored in the normal, borderline and clinical range, respectively, compared with $90.3 \%, 9.7 \%$ and $0.0 \%$, respectively, in the control group $(P<0.01)$. With respect to the results of the Thought Problems syndrome scale, $66.7 \%, 24.2 \%$ and $9.1 \%$ of the women in the TXS group scored in the normal, borderline and clinical range, respectively, compared with $96.8 \%, 3.2 \%$ and $0.0 \%$, respectively, in the control group $(P<0.01)$.

The SRS-A T-scores are summarised in Table 2 . We found that the women in the TXS group had significantly higher scores on all four SRS-A subscales compared with the control group, with medium effect sizes. With respect to functioning, we found that $62.5 \%$ of the women in the TXS group were in either the high-functioning or normal-functioning range compared with $96.8 \%$ of the control group; in contrast, $37.5 \%$ of the women in the TXS group had either mild/moderate or severe deficits compared with only $3.2 \%$ of the control group ( $P=0.002$; Table 3$)$.

\section{Relationship between full-scale IQ and SRS-A score}

We found no significant correlation between full-scale IQ and total SRS-A score in either the TXS group $\left(r_{s}=-0.30, P=0.11\right)$ or the control group $\left(r_{s}=-0.08, P=0.69\right)$.

\section{Emotion recognition}

The results of the ERT are summarised in Table 4. Overall, we found that the women in the TXS group performed significantly worse than controls at recognising emotions, with mean \pm s.d. scores of $100.8 \pm 20.5$ (95\% CI 93.6-108.1) and $115.2 \pm 16.0$ (95\% CI $109.3-121.0)$, respectively $(P=0.0028)$. When we examined each emotion separately, we found that the women in the TXS group were significantly worse than the control group at recognising sadness, fear and disgust, but were similar to the control group at recognising happiness, surprise and anger.

An ANCOVA of ERT total scores, with full-scale IQ as a covariate, confirmed that the women in the TXS group performed worse than the control group at recognising emotion $(\mathrm{F}(1,60)=7.143, P=0.010$, $\left.\eta^{2}=0.106\right)$. Moreover, full-scale IQ did not significantly affect overall performance on the ERT $\left(F(1,60)=1.00, P=0.32, \eta^{2}=0.016\right)$.

Our analysis also revealed a significant correlation between ERT total score and age in both the TXS group $\left(r_{s}=-0.48, P=0.0044\right)$ and the control group $\left(r_{s}=-0.47, P=0.0072\right)$. In contrast, we found a significant correlation between ERT total score and fullscale IQ in the TXS group $\left(r_{s}=0.36, P=0.045\right)$, but not in the control group $\left(r_{s}=0.08, P=0.65\right)$.

\section{Relationship between SRS-A and ERT score}

Lastly, we found a significant correlation between the SRS-A social motivation subscale and ERT total score in the TXS group $\left(r_{s}=0.51\right.$, $P=0.004)$, but not in the control group $\left(r_{s}=-0.10, P=0.59\right)$.

\section{Explorative comparison between the prenatally diagnosed and postnatally diagnosed women in the TXS group}

Finally, we compared the women in the TXS group who were diagnosed prenatally with those who were diagnosed postnatally. We found that these two subgroups did not differ with respect to fullscale IQ (mean values of $86.7 \pm 7.6$ (95\% CI 80.8-92.5) v. $85.9 \pm$ 11.5 (95\% CI 80.8-90.9), respectively; $P=0.85$ ); SRS-A total score (median values of 56.5 (IQR 52-60) v. 59.5 (IQR 50.5-65.5), respectively; $P=0.63)$; or total ERT score $(\mathrm{F}(2,29)=3.48, P=0.09)$.

\section{Discussion}

Here, we report the results of the first study designed to investigate social functioning and emotion recognition in adults with TXS. ${ }^{5,14}$ 


\begin{tabular}{|c|c|c|c|c|c|c|}
\hline & \multicolumn{2}{|c|}{ Triple $X$ group $(n=32)$} & \multicolumn{2}{|c|}{ Control group $(n=31)$} & \multirow[b]{2}{*}{$P$-value ${ }^{a}$} & \multirow[b]{2}{*}{ Effect size $^{b}$} \\
\hline & Median & IQR & Median & IQR & & \\
\hline Social motivation (range 37-98) & 60.0 & $51.0-67.0$ & 47.0 & $43.0-52.0$ & 0.0001 & 0.5 \\
\hline Social communication (range 37-109) & 60.0 & $48.5-62.5$ & 47.0 & $39.5-52.0$ & 0.0001 & 0.5 \\
\hline Social awareness (range 35-108) & 56.0 & $49.0-65.0$ & 45.0 & $40.0-53.0$ & 0.0005 & 0.4 \\
\hline Rigidity and repetitive behaviour (range 40-113) & 54.0 & $48.0-66.0$ & 46.0 & $42.0-52.0$ & 0.0014 & 0.4 \\
\hline Total score (36-114) & 58.5 & $51.0-64.5$ & 45.0 & $41.0-52.0$ & $<0.0001$ & 0.5 \\
\hline
\end{tabular}

\begin{tabular}{|c|c|c|c|c|}
\hline & $\begin{array}{c}\text { High } \\
\text { functioning }\end{array}$ & $\begin{array}{c}\text { Normal } \\
\text { functioning }\end{array}$ & $\begin{array}{l}\text { Mild-to- } \\
\text { moderate } \\
\text { deficits }^{c}\end{array}$ & $\begin{array}{l}\text { Severe } \\
\text { deficits }^{d}\end{array}$ \\
\hline $\begin{array}{l}\text { Triple } \times \text { group } \\
\qquad(n=32)\end{array}$ & 1 & 19 & 7 & 5 \\
\hline $\begin{array}{l}\text { Control group } \\
\qquad(n=31)\end{array}$ & 5 & 25 & 1 & 0 \\
\hline \multicolumn{5}{|c|}{$\begin{array}{l}\text { SRS-A, Social Responsiveness Scale for Adults; TXS, triple X syndrome. } \\
\text { a. Defined as a T-score of 0-39. } \\
\text { b. Defined as a T-score of } 40-59 \text {. } \\
\text { c. Defined as a T-score of } 60-74 \text {. } \\
\text { d. Defined as a T-score of } \geq 75 \text {. }\end{array}$} \\
\hline
\end{tabular}

Consistent with our hypothesis, we found that women with TXS have reduced social functioning compared with a control group. We found that the women in the TXS group performed significantly worse than the control group with respect to recognising emotions, particularly sadness, fear and disgust. We found no significant correlation between full-scale IQ and total SRS-A score.

Our results are consistent with previous reports that girls with TXS can experience social impairments, have inadequate social skills and live a relatively isolated life. ${ }^{23,24}$ Thus, these findings suggest that TXS could be a risk factor for developing autism and/or autism-related conditions with impaired social functioning.

Previous studies analysed the data separately between prenatally diagnosed TXS and postnatally diagnosed TXS. ${ }^{25,41,42}$ In our study, we analysed all of the women with TXS group as a single group, for several reasons. We did not find differences in full-scale IQ, social responsiveness and emotion recognition between prenatally and postnatally diagnosed women. Therefore, we choose to report the results for the complete TXS sample, to increase statistical power.

Importantly, we estimated that the level of bias was relatively low in our sample, although (as in all studies involving sex chromosome disorders) our results may have been influenced to some extent by ascertainment bias, ${ }^{5,25}$ given that higher functioning patients are often not clinically identified. Nevertheless, $82.4 \%$ of the women in our TXS group were diagnosed for a reason other than behavioural problems or learning difficulties. Although many studies have a general risk of bias in favour of healthier participants, leading to an under-recruitment of participants with social impairments $\mathrm{s}^{25}$ and/or reduced social functioning, ${ }^{4,43}$ our results are similar to previous reports with respect to impaired social functioning ${ }^{23,24}$ and reduced full-scale $\mathrm{IQ}^{22,44}$ in unbiased groups with TXS, and therefore likely represent impaired social functioning among adults with TXS. Thus, we conclude that our sample reliably reflects differences in social impairments between women with and without TXS in the general population.

To the best of our knowledge, this is the first study designed to examine emotion recognition in adults with TXS, although emotion recognition and face processing have been extensively studied in

\begin{tabular}{|c|c|c|c|c|c|c|}
\hline \multirow{2}{*}{$\begin{array}{l}\text { Facial } \\
\text { expression } \\
\text { (range 0-30) }\end{array}$} & \multicolumn{2}{|c|}{$\begin{array}{l}\text { Triple } \times \text { group } \\
\quad(n=33)\end{array}$} & \multicolumn{2}{|c|}{$\begin{array}{l}\text { Control group } \\
\qquad(n=31)\end{array}$} & \multirow{2}{*}{$\begin{array}{c}P- \\
\text { value }^{a}\end{array}$} & \multirow{2}{*}{$\begin{array}{l}\text { Effect } \\
\text { size }^{\text {b }}\end{array}$} \\
\hline & Median & IQR & Median & IQR & & \\
\hline Sadness & 17 & 14-19 & 20 & $17-23$ & 0.002 & 0.4 \\
\hline Fear & 10 & 5-12 & 13 & 8-18 & 0.006 & 0.4 \\
\hline Disgust & 14 & 9-19 & 21 & $17-23$ & 0.012 & 0.3 \\
\hline Happy & 25 & $22-26$ & 26 & $23-28$ & 0.069 & 0.2 \\
\hline Surprise & 23 & $18-25$ & 22 & $20-25$ & 0.984 & 0.0 \\
\hline Anger & 17 & $15-18$ & 16 & $15-18$ & 0.957 & 0.0 \\
\hline \multicolumn{7}{|c|}{$\begin{array}{l}\text { TXS, triple X syndrome; IQR, interquartile range. } \\
\text { a. Mann-Whitney } U \text {-test. } \\
\text { b. Effect size was calculated with the equation: } r=Z / \sqrt{ } N \text {. }\end{array}$} \\
\hline
\end{tabular}

ASD, albeit with conflicting results. For example, compared with controls, individuals with ASD can have an atypical gaze pattern; whereas most individuals fixate on the eyes, individuals with ASD generally gaze at other parts of the face, such as the nose or mouth. ${ }^{45}$ Similarly, individuals with Turner syndrome often fixate on the mouth region rather than on the eyes, particularly when looking at a face expressing fear. ${ }^{46}$ It is therefore possible that women with TXS may also fixate on regions of the face other than the eyes, thus affecting their ability to recognise specific emotions as sadness and fear. In addition, being confronted with a sad or fearful face could result in gaze avoidance by individuals who may be sensitive, easily hurt emotionally and/or easily upset, attributes that that have been associated with TXS. $^{2}$ Viewing disgust in a face can also affect individuals with low self-esteem, another property that has been reported in TXS. ${ }^{2,6}$ Finally, increased feelings of depression and/or anxiety can cause a bias toward identifying negative emotions such as sadness and fear, particularly during a forced choice task paradigm such as the ERT used in our study. ${ }^{45}$

Interestingly, we found an association between improved performance on the ERT and a higher level of impairment in the social motivation subdomain of the SRS-A in the TXS group, but not in the control group. Moreover, we found that the ability to recognise emotions appeared to be age-dependent in both the TXS group and the control group, with performance on the ERT decreasing with age.

Our finding that emotion recognition decreases with increasing levels of social motivation in the TXS group was somewhat unexpected, although such an association has been described previously. ${ }^{45,47}$ Abnormal processing of facial expressions has been suggested to be independent of social functioning, as individuals with intact emotion recognition can experience difficulties in social functioning. ${ }^{45}$ The relationship between social motivation and emotion recognition is complex and was studied recently by Garman et al in a relatively small group of individuals with ASD, most of whom were boys. ${ }^{47}$ The authors found that participants 
with higher social motivation generally performed worse at recognising emotions, whereas lower social motivation was correlated with improved recognition of emotion, particularly anger, in children's faces. Thus, the relationship between social motivation and emotion recognition is clearly complex, and appears to depend on the participant's age, the emotion being expressed and whether the emotion is expressed by children or adults. Additional study regarding the development of emotion recognition and social motivation is needed to understand our findings and may provide valuable insight into social development in general.

Further study regarding the genetic and other factors that contribute to the clinical variability in TXS may provide new insights into TXS, as well as gender-related differences in ASD in general. ${ }^{48}$ In this respect, questions regarding TXS and social functioning warrant further study; for example, the relationship between social functioning and societal functioning and the relationship between social functioning and impaired language and communication, thus providing new treatment options relevant to women with TXS, their families and caregivers.

\section{Strengths and limitations}

Although this is the first study to examine social functioning and emotion recognition in adults with TXS, certain limitations must be considered when interpreting the results. First, although the SRS-A is a widely accepted screening instrument for ASD, it is not considered a diagnostic instrument. Therefore, we can only make statements regarding impaired social functioning regardless of the presence of ASD. Second, we did not assess social anxiety or linguistic function, factors that could have affected our measure of impaired social functioning. Third, the ERT contains 90 specific stimuli, with six emotions expressed at 15 different intensities. Although it can be difficult in practice to distinguish among the lowest intensities, during the task the participant is required to select an intensity, which can cause the participant to guess to some degree when presented with stimuli with low intensity. Finally, the ERT was the final task performed in the neuropsychological test battery, which could have led to tiredness and/or frustration, particularly in the women with TXS, thereby affecting the results. $^{2}$ We repeat what was discussed above that there is no study on sex chromosome disorders without any risk of bias, including this study.

In conclusion, our results indicate that adults with TXS have impaired social functioning and emotion recognition. Thus, the role of $\mathrm{X}$ chromosome aneuploidy in this social impairment should be examined to explain the variability in phenotypic presentation. Nevertheless, TXS may serve as a suitable model for studying the effect of genetics on social cognition and behaviour, particularly in females.

\footnotetext{
Maarten Otter (D), Department of Psychiatry and Neuropsychology, School for Mental Health and Neuroscience, Maastricht University, The Netherlands; Department of Forensic Psychiatry \& Mild Intellectual Disabilities, STEVIG, The Netherlands; and Department of Community Mental Health in Mild Intellectual Disabilities, Trajectum, The Netherlands; Peter M. L. Crins (1D), Department of Psychiatry and Neuropsychology, School for Mental Health and Neuroscience, Maastricht University, The Netherlands; Bea C. M. Campforts, Department of Psychiatry and Neuropsychology, School for Mental Health and Neuroscience, Maastricht University, The Netherlands; Constance T. R. M. Stumpel, Department of Clinical Genetics and School for Oncology and Developmental Biology, Maastricht University Medical Centre, The Netherlands; Thérèse A. M. J. van Amelsvoort, Department of Psychiatry and Neuropsychology, School for Mental Health and Neuroscience, Maastricht University, The Netherlands; Claudia Vingerhoets, Department of Psychiatry and Neuropsychology, School for Mental Health and Neuroscience, Maastricht University, The Netherlands; Heeren Loo Zorggroep, The Netherlands; and Department of Radiology and Nuclear Medicine, Amsterdam University Medical Centre, The Netherlands

Correspondence: Dr Maarten Otter. Email: m.otter@maastrichtuniversity.n

First received 1 Aug 2020, final revision 23 Dec 2020, accepted 27 Dec 2020
}

Data availability

The data in this study are not publicly available.

\section{Supplementary material}

Supplementary material is available online at https://doi.org/10.1192/bjo.2021.8

\section{Acknowledgements}

We are grateful to the Triple X support network in The Netherlands for their support in recruiting participants with TXS and controls, as well as their helpful input when designing this study.

\section{Author contributions}

M.O., C.T.R.M.S. and T.A.M.J.V.A. formulated the research questions. M.O. and T.A.M.J.V.A. designed the study. M.O. and B.C.M.C. performed the study. M.O., P.M.L.C. and C.V. analysed the data, and M.O., C.T.R.M.S., T.A.M.J.V.A. and C.V. wrote the manuscript, with input from all other authors.

\section{Funding}

This research was not supported by any specific grant from any funding agency, commercial enterprise or not-for-profit sector

\section{Declaration of interest}

\section{None.}

ICMJE forms are in the supplementary material, available online at https://doi.org/10.1192/ bjo.2021.8

\section{References}

1 Jacobs PA, Baikie AG, Court Brown WM, MacGregor TN, Maclean N, Harnden DG. Evidence for the existence of the human "super female". Lancet 1959; 274: 423-5.

2 Otter M, Schrander-Stumpel CTRM, Curfs LM. Triple X syndrome: a review of the literature. Eur J Hum Genet 2010; 18(3): 265-71.

3 Viuff MH, Stochholm K, Uldbjerg N, Nielsen BB, Danish Fetal Medicine Study G, Gravholt $\mathrm{CH}$. Only a minority of sex chromosome abnormalities are detected by a national prenatal screening program for Down syndrome. Hum Reprod 2015; 30(10): 2419-26.

4 Tuke MA, Ruth KS, Wood AR, Beaumont RN, Tyrrell J, Jones SE, et al. Mosaic Turner syndrome shows reduced penetrance in an adult population study. Genet Med 2019; 21(4): 877-86.

5 Skuse D, Printzlau F, Wolstencroft J. Sex chromosome aneuploidies. Handb Clin Neurol 2018; 147: 355-76.

6 Freilinger P, Kliegel D, Hanig S, Oehl-Jaschkowitz B, Henn W, Meyer J. Behaviora and psychological features in girls and women with triple-X syndrome. $A m \mathrm{~J}$ Med Genet A 2018; 176(11): 2284-91.

7 Otter M, Stumpel CTRM, van Amelsvoort T. Client-centred clinical genetic diagnostics. Adv Ment Health Intell Disabil 2018; 12(1): 1-10.

8 Otter M, Schrander-Stumpel CT, Didden R, Curfs LM. The psychiatric phenotype in triple $\mathrm{X}$ syndrome: new hypotheses illustrated in two cases. Dev Neurorehabil 2012; 15(3): 233-8.

9 Stochholm K, Juul S, Gravholt CH. Poor socio-economic status in 47,XXX -an unexpected effect of an extra X chromosome. Eur J Med Genet 2013; 56(6): 286-91.

10 Morel A, Peyroux E, Leleu A, Favre E, Franck N, Demily C. Overview of socia cognitive dysfunctions in rare developmental syndromes with psychiatric phenotype. Front Pediatr 2018; 6: 102.

11 Cotter J, Granger K, Backx R, Hobbs M, Looi CY, Barnett JH. Social cognitive dysfunction as a clinical marker: a systematic review of meta-analyses across 30 clinical conditions. Neurosci Biobehav Rev 2018; 84: 92-9.

12 Raznahan A, Parikshak NN, Chandran V, Blumenthal JD, Clasen LS, AlexanderBloch $A F$, et al. Sex-chromosome dosage effects on gene expression in humans. Proc Natl Acad Sci USA 2018; 115(28): 7398-403.

13 Jowhar Z, Shachar S, Gudla PR, Wangsa D, Torres E, Russ JL, et al. Effects of human sex chromosome dosage on spatial chromosome organization. $\mathrm{Mol}$ Biol Cell 2018; 29(20): 2458-69.

14 Green T, Flash S, Reiss AL. Sex differences in psychiatric disorders: what we can learn from sex chromosome aneuploidies. Neuropsychopharmacology 2019; 44(1): 9-21.

15 Bishop DV, Jacobs PA, Lachlan K, Wellesley D, Barnicoat A, Boyd PA, et al. Autism, language and communication in children with sex chromosome trisomies. Arch Dis Child 2011; 96(10): 954-9. 
16 Navarro-Cobos MJ, Balaton BP, Brown CJ. Genes that escape from X-chromosome inactivation: potential contributors to Klinefelter syndrome. Am J Med Genet C Semin Med Genet 2020; 184(2): 226-38.

17 Hong DS, Hoeft F, Marzelli MJ, Lepage JF, Roeltgen D, Ross J, et al. Influence of the $\mathrm{X}$-chromosome on neuroanatomy: evidence from Turner and Klinefelter syndromes. J Neurosci 2014; 34(10): 3509-16.

18 Zhang Y, Castillo-Morales A, Jiang M, Zhu Y, Hu L, Urrutia AO, et al. Genes that escape $\mathrm{X}$-inactivation in humans have high intraspecific variability in expression, are associated with mental impairment but are not slow evolving. $\mathrm{Mol}$ Biol Evol 2013; 30(12): 2588-601.

19 Robinson A, Lubs HA, Nielsen J, Sorensen K. Summary of clinical findings: profiles of children with 47,XXY, 47,XXX and 47, XYY karyotypes. Birth Defects Orig Artic Ser 1979; 15(1): 261-6.

20 Stewart DA, Netley CT, Park E. Summary of clinical findings of children with 47 XXY, 47,XYY, and 47,XXX karyotypes. Birth Defects Orig Artic Ser 1982; 18(4): $1-5$

21 Netley CT. Summary overview of behavioural development in individuals with neonatally identified X and Y aneuploidy. Birth Defects Orig Artic Ser 1986; 22(3): 293-306

22 Robinson A, Bender BG, Linden MG. Summary of clinical findings in children and young adults with sex chromosome anomalies. Birth Defects Orig Artic Ser 1990; 26(4): 225-8.

23 Götz M. The Psychiatric Consequences of Sex Chromosome Abnormalities: A Cohort Study. University of Edinburgh, 1996.

24 Linden MG, Bender BG, Harmon RJ, Mrazek DA, Robinson A. 47, XXX: what is the prognosis? Pediatrics 1988; 82(4): 619-30.

25 Wilson AC, King J, Bishop DVM. Autism and social anxiety in children with sex chromosome trisomies: an observational study. Wellcome Open Res 2019; 4(32): 32 .

26 Lenroot RK, Blumenthal JD, Wallace GL, Clasen LS, Lee NR, Giedd JN. A casecontrol study of brain structure and behavioral characteristics in 47, XXX syndrome. Genes Brain Behav 2014; 13(8): 841-9.

27 Derogatis LR, Unger R. Symptom Checklist-90-Revised. The Corsini Encyclopedia of Psychology. John Wiley \& Sons, 2010

28 van Elst $\mathrm{PC}$, Otter $\mathrm{M}$, Wijnen $\mathrm{F}$, Junge $\mathrm{C}$. Evaluating the Scope of Language Impairments in a Patient with Triple $\mathrm{X}$ Syndrome: A Brief Report. Dev Neurorehabil 2020; 23(6): 402-406.

29 Urbanus E, van Rijn S, Swaab H. A review of neurocognitive functioning of children with sex chromosome trisomies: identifying targets for early intervention. Clin Genet 2020; 97(1): 156-67.

30 Babinet MN, Rigard C, Peyroux E, Dragomir AR, Plotton I, Lejeune H, et al. [Socia cognition disorders in Klinefelter syndrome: a specific phenotype? (KS)] Encephale 2017; 43(5): 423-8

31 van Rijn S, Swaab H, Aleman A, Kahn RS. X Chromosomal effects on socia cognitive processing and emotion regulation: a study with Klinefelter men (47,XXY). Schizophr Res 2006; 84(2-3): 194-203.

32 Wolstencroft J, Skuse D. Social skills and relationships in Turner syndrome. Curr Opin Psychiatry 2019; 32(2): 85-91.
33 Velthorst E, Levine SZ, Henquet C, de Haan L, van Os J, Myin-Germeys I, et al. To cut a short test even shorter: reliability and validity of a brief assessment of intellectual ability in schizophrenia-a control-case family study. Cogn Neuropsychiatry 2013; 18(6): 574-93.

34 Achenbach TM, Rescorla LA. Manual for the ASEBA Adult Forms \& Profiles. University of Vermont, Research Center for Children, Youth, \& Families, 2003.

35 Tenneij $\mathrm{NH}$, Koot HM. A preliminary investigation into the utility of the Adult Behavior Checklist in the assessment of psychopathology in people with low IQ. J Appl Res Intellect Disabil 2007; 20(5): 391-400.

36 Chan W, Smith LE, Hong J, Greenberg JS, Mailick MR. Validating the Social Responsiveness Scale for adults with autism. Autism Res 2017; 10(10): 1663-71.

37 Constantino JN, Gruber CP, Noens IL, De la Marche MF, Scholte EM. SRS-A the Social Responsiveness Scale for Adults (Dutch manual). Hogrefe, 2012.

38 Constantino JN, Gruber CP. Social Responsiveness Scale: Manual. Western Psychological Services, 2005

39 De la Marche W, Noens I, Luts J, Scholte E, Van Huffel S, Steyaert J. Quantitative autism traits in first degree relatives: evidence for the broader autism phenotype in fathers, but not in mothers and siblings. Autism 2012; 16(3): 247-60.

40 Cambridge Cognition, Emotion Recognition Task (ERT). In CANTAB Research Suite 6 Test Administration Guide: Ch. 10. Cambridge Cognition Ltd, 2014.

41 Robinson A, Bender BG, Linden MG. Prognosis of prenatally diagnosed children with sex chromosome aneuploidy. Am J Med Genet 1992; 44(3): 365-8.

42 Wigby K, D'Epagnier C, Howell S, Reicks A, Wilson R, Cordeiro L, et al. Expanding the phenotype of Triple $X$ syndrome: a comparison of prenatal versus postnatal diagnosis. Am J Med Genet A 2016; 170(11): 2870-81.

43 Fry A, Littlejohns TJ, Sudlow C, Doherty N, Adamska L, Sprosen T, et al. Comparison of sociodemographic and health-related characteristics of UK biobank participants with those of the general population. Am J Epidemiol 2017; 186(9): 1026-34.

44 Ratcliffe SG, Murray L, Teague P. Edinburgh study of growth and development of children with sex chromosome abnormalities. III. Birth Defects Orig Artic Ser 1986; 22(3): 73-118.

45 Webb SJ, Neuhaus E, Faja S. Face perception and learning in autism spectrum disorders. Q J Exp Psychol (Hove) 2017; 70(5): 970-86.

46 Mazzola F, Seigal A, MacAskill A, Corden B, Lawrence K, Skuse DH. Eye tracking and fear recognition deficits in Turner syndrome. Soc Neurosci 2006; 1(3-4): 259-69.

47 Garman HD, Spaulding CJ, Webb SJ, Mikami AY, Morris JP, Lerner MD. Wanting it too much: an inverse relation between social motivation and facial emotion recognition in autism spectrum disorder. Child Psychiatry Hum Dev 2016; 47(6): 890-902.

48 Wainer-Katsir $\mathrm{K}$, Linial $\mathrm{M}$. Chromosome $\mathrm{X}$ factors and phenotype variability. Obstet Gynecol Rep 2019; 3(1): 1-3.

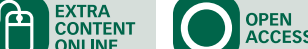

